Article

\title{
Experimenting with Circularity When Designing Contemporary Regions: Adaptation Strategies for More Resilient and Regenerative Metropolitan Areas of Amsterdam and Naples Developed in University Studio Settings
}

\author{
Libera Amenta ${ }^{1,2, *(D)}$ and Lei Qu ${ }^{2, * \mathbb{D}}$ \\ 1 Department of Architecture (DiARC), University of Naples Federico II (UNINA), 80134 Naples, Italy \\ 2 Department of Urbanism, Delft University of Technology (TU Delft), 2628 BL Delft, The Netherlands \\ * Correspondence: libera.amenta@unina.it (L.A.); L.Qu@tudelft.nl (L.Q.); Tel.: +39-3201435079 (L.A.)
}

Received: 19 April 2020; Accepted: 29 May 2020; Published: 3 June 2020

\begin{abstract}
This paper aims to demonstrate how 'research by design,' which is an approach bridging research, design, and planning, can help unpack the complexity of today's metropolitan challenges by considering the resource flows and processes that were omitted by traditional ways of planning. This is crucial for circular developments. By reporting the experience of two university design studios across Europe, this paper can contribute to a better understanding and imagination of desirable future scenarios of resilient regions. The experiments carried out in the Regional design studio: 'Spatial Strategies for the Global Metropolis' held at TU Delft are described alongside with the exercises carried out in the design studio 'Laboratory of Urbanism' of the MAPA Course, held at DiARC UNINA. Both courses focused on the regeneration of wastescapes as a fundamental part of holistic adaptation strategies for more resilient and circular regions. Climate change issues related to resilience thinking have been interwoven with other complex challenges such as the co-existence of wastescapes and land scarcity as well as spatial injustice. Through a 'research by design' approach, these different aspects are brought together to achieve a holistic approach for urban resilience.
\end{abstract}

Keywords: 'research by design'; resilient cities; wastescapes; adaptive reuse; urban metabolism; circular economy

\section{Introduction: Set the Context for Circularity Approaches}

Contemporary metropolitan regions are facing increasing challenges caused by the complexity of all the resource flows and processes that were omitted by traditional ways of planning [1], and due to interwoven global issues, such as scarcity of resources [2] and related ecological deficit [3] as well as excess of wasted materials and neglected land, namely drosscapes [4] and wastescapes $[5,6]$, and flooding risks brought by climate change, pollution, and further environmental hazards. These challenges are mixed, and they occur simultaneously. Therefore, they cannot be handled separately any longer by traditional and sectorial ways of spatial planning and land development. The latter usually disturbed the natural metabolism of ecosystems, the natural water cycles $[7,8]$, and facilitated linear models of economic development (based on the logic 'use-consume-dispose') such as the modern food industry that extracts continuously finite resources and harms natural systems [9], and eventually produces a significant amount of waste.

Thus, fundamental changes to the ways cities and regions are currently planned and developed are in urgent need. In fact: "our current way of producing and consuming has a huge impact on 
the environment and on our society. Scarce raw materials are running out [...] Nobody wants to live in a throwaway society or contribute to poor working conditions in low-wage countries" [10]. This requires a thorough understanding of the way natural and human systems work, of the flows of resources and of the possible ways of integration of such flows in spatial planning. Thus, seeking more circular and regenerative development could enhance urban resilience. The latter is referred to as the capacity of urban systems to readjust quickly in relation to any possible risk, achieving a new equilibrium [11]. Such new ways of planning should not be the only evidence-based/scientific idea aimed at the understanding of the complex metabolic nature of the regional context, but also explorative at the same time and prone to search for more desirable future scenarios.

The main knowledge gap identified in this paper is related to linking the two above-mentioned dimensions of 'scientific research' and 'explorative design' methodologically to achieve a comprehensive understanding of today's complex issues, and to be able to intervene in this complexity. Approaches of 'research by design' emerged increasingly in the practice of professionals and education in urban planning and design, and have generated new knowledge and insights into the built environment, but they are not often communicated by publications [12]. Furthermore, the methodology of 'research by design' in the field of sustainable urban and regional development is not yet clarified. There are many different interpretations of it and every case study that involves design seems to be labelled as 'research by design' [13]. This has hindered the development of systematic ways of design thinking in tackling the global challenges mentioned above.

Another knowledge gap lies in managing resource flows in spatial planning and design by using wastescapes characterisation $[5,6,14,15]$. It is recognized that the current conceptualization of the Circular Economy (CE) is inadequate when applying to cities with one of the issues being the exclusion of understanding land as a resource [16]. This paper intends to stress the importance of an emerging approach that focuses on the valorisation of the areas traditionally considered as marginal and neglected as wastescapes. This means innovative resources are re-inputted in the metabolic flows of contemporary regions to face the scarcity of raw materials and fertile soil.

Aiming to overcome these knowledge gaps, this paper introduces the work developed within two university design studios at the master level held at Delft University of Technology in The Netherlands (TU Delft), and at the University of Naples Federico II in Italy (UNINA). The methodological structure of these laboratory courses is very much aligned since they share their main premises and approaches. In fact, first of all, they both took into consideration the regional and territorial scale. Second, they recognised the importance of managing different scales and disciplines at the same time, by applying a systemic methodology. Third, they have been based on Circular Economy and circular metabolism approaches. Lastly, both courses focused on one of the two pilot cases investigated within the EU funded Horizon 2020 project entitled "REPAiR-Resource Management in Peri-urban Areas: Going Beyond Urban Metabolism", namely the Metropolitan Areas of Amsterdam and Naples (The two design studios, by building upon the knowledge developed by the ongoing above-mentioned project REPAiR, applied a rather new approach, going beyond urban metabolism toward identifying eco-innovative solutions and strategies for a better management of material and territorial resources, namely wastescapes, in peri-urban areas. Both courses incorporated the REPAiR approach in the existing cultures of design education at TU Delft and UNINA, which have traditions of using 'research by design' as the methodology for interdisciplinary projects in design studios (e.g., including landscape perspectives). Special attention is given to peri-urban areas and their characteristic of being territories in-between urban and rural settlements. Particularly, peri-urban territories can be described as 'hybrid' geographies [17,18], which are fragmented because of the presence of large infrastructure networks, industrial areas, large buildings, and a huge number of single-family-houses. They generally welcome all the facilities for the waste disposal and management. "The conventional idea of a gradual transition in spatial structure from urban to rural does not properly reflect contemporary patterns of urban development and their potential for sustainable development" [19]. This is due to the fact that peri-urban areas are usually characterised by an intermingling of built and unbuilt features with 
unplanned or obsolete uses of land. Such areas are often bypassed in regional development strategies. However, they possess great potential for adaptive strategies [20]. These common grounds made the comparison of the two courses meaningful, especially when drawing conclusions on adaptive strategies for resilient and regenerative metropolitan regions. Nevertheless, these two courses had different essences. The TU Delft course focused more on regional design. It used explorative spatial design proposals to connect understanding of the region (its spatial conditions, socio-economic trends, resource flows, and governance), envisioning of more desirable (resilient/circular) future scenarios, and strategy-making (strategic interventions with timeframes). It was evidence-based and supported by a situated learning environment [21]. The UNINA course focused on the analysis of the complexity of the case study area by giving great attention toward the understanding phase, which leads to a holistic approach to adaptivity/resilience. The design strategies focused deeper on a relatively smaller scale than the TU Delft regional design course by selecting a 'Sample Area' where to simulate the implementation of the project choices. Such differences in experimenting with design solutions complement each other by filling in the knowledge gaps mentioned above.

\section{Defining Theories and Concepts}

\section{1. 'Research by Design' as the Framework: Understanding and Interpreting the Regional and Local Scales}

Studies demonstrated that "research by design is a great tool for understanding urban systems and identifying opportunities to improve them" [22] (p. 120), especially in relation with the "wicked problems' of the contemporary cities such as climate change, scarcity of resources, and environmental threats, which are clustered, and could be solved through an interdisciplinary approach and collaboration among different parties [22].

While research provides knowledge into the issues at hand, with scientific quest of 'how things are', design contributes to shaping the world on 'how things can be.' The process of analyzing and synthesizing lies in between. However, in the field of spatial planning and design, such an in-between zone is not much explored, as planners and designers have not fully used scientific knowledge of various disciplines to develop new models of development, and (social, economic, and environmental) scientists seldom translate their acquired knowledge into spatial planning and design assignments. To cope with complex future challenges and 'wicked problems,' alternative ways of planning and design are needed, which call for an end to the dichotomy of research and design by identifying solutions that could be adaptive and flexible toward unforeseen changes. According to 'the diagram of dual processing research' developed by Wall and $\mathrm{CHO}$, design and scientific research follow similar processes of conceptualization (from observation to theoretical underpinning), but differ significantly in the process of operationalization in which design research involves "subjective choices, multiple hypotheses, contextuality, non-repeatability, specificity, and coincidence" while scientific research involves "objective choices, individual hypotheses, universality, repeatability, generalization, and cause and effect" [23]. The dual processing research indicates that the scientific and design worlds need to reach a higher level of interaction, so that mutual understanding and spillovers are stimulated. This refers to a cyclic process in which conclusions from scientific research inform design and design outcomes become feedback for the start of scientific research.

'Research by design,' which is the approach utilised in this paper, is in line with such a framework. It is a further development toward interdisciplinarity based on the Dutch planning tradition. Furthermore, the exhibition 'Nederland Nu Als Ontwerp' (NNAO) organised in the 1980s has been regarded as the starting point of this approach, which helped envision scenarios that constitute a possible image of the future of the Netherlands in 2050 [22]. In this context, design is becoming a tool to explore spatial potentials and generate desirable future scenarios, which are possible but might be unexpected [24], and test the effects of alternative interventions. In this sense, the role of spatial design is not anymore limited to giving forms to intended use, but also testing, evaluating, and validating 
unexpected forms of use, which has a research dimension with it such as research by (explorative) design [12].

As mentioned earlier, such methodological thinking has been applied increasingly in practice and education in the field of urban and regional planning and design so far. While the ongoing global challenges have brought up the importance of the regional level, 'regional design', as urbanism on the regional scale, is gaining progressively more attention. The term of 'regional design' itself might sound still new to many since it can have various names and definitions in different planning contexts. However, generally speaking, it existed, and it has been the backbone for spatial planning as a tool for spatial strategy and spatial management. In recent years, 'regional design' has become topical again due to the demand for strategic solutions that can deal with the new conditions of urbanization. These new conditions include globalization, climate change, migration, and so on, which play a crucial role on a new urban scale: city-regional scale. It can only be tackled with spatial strategies at the matching scale [25]. Traditionally, 'regional design' shapes the physical form of regions to accommodate the growth and guide the development with spatial frameworks. This involves flows of people and goods by managing the resource flows such as waste, energy, and soil to 'regional design' [26]. Therefore, this poses a new challenge to 'regional design' itself when CE is brought to the spatial development agenda. What are the spatial implications of the current linear model of economy? How should the transition towards a CE with new spatial strategies be stimulated? These research questions require interdisciplinary methods that bring together scientific disciplines of industrial ecology and expertise of spatial planning, landscape, and design. Furthermore, input from different stakeholders is of great importance in understanding the issues, and potentials of places, and testing solutions by establishing a transdisciplinary approach. This explains the fact that the two design studios of TU Delft and UNINA built on the knowledge developed by the REPAiR project with the expectation that scientific research and design feed and benefit from each other. In this sense, students could be considered as active participants of the Peri-Urban Living Labs implemented by the REPAiR project for each of the case studies (e.g., Amsterdam and Naples peri-urban areas) in order to experiment Eco-Innovative Solutions $[27,28]$. This is done by combining "areas of expertise from diverse fields of knowledge (e.g., landscape architecture, design, industrial ecology, spatial planning, civil engineering, urban planning, ... and technically diversified competences represented by people, leaders, politics, students, and other relevant local stakeholders' knowledge), in order to understand the current criticalities as well as to envision future development possibilities in an integrative way" [29] (p. 7).

'Research by design' could contribute to such an experimentation both at the regional level (as has been applied thoroughly in the TU Delft course) as well as at the local scale (such as the eco-innovative solutions developed by students of the UNINA course, which cross different scales of deepening). Both courses showcased the application of 'research by design' based on a holistic understanding of regional challenges and local interventions. Therefore, both courses have applied multi-scalar approaches in the development of design proposals, in which analyzing and synthesizing processes are stimulated, so as to facilitate a thorough interaction between research and design. Knowledge from the REPAiR project has been used as input for design studios on theoretical understanding and empirical data related to $\mathrm{CE}$ while the outputs of the design studios provided new insights, which could be useful for research to eventually evaluate spatial implications of new CE models.

\subsection{Towards Circular and Resilient Approaches for Peri-Urban Areas: Urban Metabolism and Circular Economy as Background Knowledge}

This paper discusses the importance and urgency of a paradigm change for the actual unsustainable linear model of growth by exploring the work done within the two above-mentioned design studios. They both built upon the theories of urban metabolism (UM) [30-32], which enables researchers, students, designers, and planners to outline the metabolic functionalities of contemporary regions and circular economy [33-36] by applying them to the study of the two peri-urban areas of Amsterdam and Naples metropolitan regions. 
Urban Metabolism is a metaphor understanding cities as ecosystems characterised by inflows and outflows of goods, materials, energy, and people. Moreover, UM is a way to potentially improve the sustainability of the resource management systems at the different regional and city scales [37]. Today it is a widespread concept embracing several aspects including physical, environmental, technical dimensions regarding material and immaterial flows. UM is considered both as a framework to understand the complexity of urban ecosystems-'metabolism is a precondition of life' [38] — but also as 'a framework for modelling complex urban systems' material and energy streams [38]. Therefore, metabolism can be seen as a conceptualisation for reading, interpreting, and designing contemporary urban regions.

UM-besides focusing on the flows that characterise the mechanisms of cities-deals with socio-economic dimensions, as fundamental as the technical ones. Thus, the social dimension of metabolism [22] is intertwined with topics like spatial justice and equal access to opportunities, including social and political aspects of daily life in contemporary cities. It has been shown that, in order to envision a better and more resilient future for our regions, it is necessary to design solutions and strategies, which will allow cities and regions to grow and prosper without overcoming the planetary boundaries [39].

Operationalising the metabolism of contemporary regions within the circular strip represented by the doughnut economy—as defined by the English economist Kate Raworth [40] —is meant to remain and operate within an equal and secure space for humanity on Earth [39], being in balance with nature. This is to achieve sustainable and resilient development, and not further damaging the resources of our planet, by helping decision-makers in defining desirable societal development [39].

Working within the planet boundaries [41] asks for stressing the importance of the reuse, recycle, and regeneration of all wasted resources (including waste and wastescapes) for improving urban resilience. Such an argument also defines the resilient and regenerative scenarios for metropolitan areas this paper intends to contribute to.

This can be achieved by applying the base principles of the Circular Economy, which foresee closed loops of resource flows toward zero waste production. "Circular economy systems keep the added value in products for as long as possible and eliminates waste." [42] (p. 2). However, focusing only on innovations related to products for circular economy is not enough, which is also necessary to deepen the importance of the reuse and re-valorization of misused land, which has been overlooked for a long time in Circular Economy approaches. In fact, Williams commented on the RESOLVE framework (acronym for Regenerate, Share, Optimise, Loop, Virtualise, Exchange) developed by Ellen MacArthur Foundation (EMF) for circular economy, pointing out that it is not considering land as a resource: "land which remains vacant because of the cost of decontamination, difficulties with land assembly or simply due to speculation, is a waste of a valuable resource. Land recycling should be facilitated in a city to optimise resource use" [16] (p. 2752).

All around Europe, peri-urban areas are characterised by hybrid functions among urban and agricultural spatial and functional organisations. Until now, peri-urban territories have been of great interest for researchers who were fascinated by the huge potentialities of these kinds of territories regarding land resources and adaptive strategies [43-45]. Research shows that starting from the potentialities of the peri-urban areas is a way to reveal the regenerative nature of this kind of territory, which opens up to various scenarios for sustainable future development. Thus, we can argue that urban metabolism and circular economy are valid approaches for the understanding and interpretation of the complex structure of peri-urban areas, which have been recognised as an extraordinary laboratory for ideas and projects, and can only be unraveled through a multi-scale approach [46].

\section{Materials and Methods: Two Design Studios across Europe}

The two design studios described in this paper held at TU Delft and UNINA were organised into two main phases: (i) analysing/mapping to understand and unpack the territorial complexity, and (ii) 
experimenting/designing to synthesize knowledge about the territory to envision better futures for the regions and sub-regions investigated, and, thus, by imagining future scenarios.

Students identified systemic solutions for both the Metropolitan Areas of Amsterdam and Naples by tackling the challenges the regions are confronted with (such as climate change, spatial justice, etc.) through the themes of $\mathrm{CE}$ (such as construction and demolition waste cycles, food and organic waste cycles, renewable energy cycles, etc.) with specific focuses on peri-urban territories and regeneration of wastescapes. The following parts of the paper attempt to analyse the key features of these courses and elements that could make the students' work/experiments interesting and relevant to research with the aim to overcome the identified knowledge gaps that this paper aims to fill. Specifically, this study deepens the different ways students used design as a tool to integrate various sources of input and envision more resilient future scenarios for urban and, specifically, for peri-urban areas.

\subsection{The Role of Explorative Design Proposals in Evidence-Based Vision Building and Strategy Making for the Metropolitan Area of Amsterdam}

The regional design studio of the course 'Spatial Strategies for the Global Metropolis' (duration: from February to April 2019) held at the Department of Urbanism, Faculty of Architecture and the Built Environment of Delft University of Technology (TU Delft) aimed to grasp the spatial organisation and the development trends of the Amsterdam Metropolitan Area (AMA), and experiment integrated spatial strategies that could stimulate the transition toward a CE (a thematic focus of sustainable development). The AMA is located in the north of the larger polycentric Randstad region and spans across the boundaries of two provinces (North Holland and Flevoland) with a total population of 2.4 million (Figure 1). The boundaries of the AMA include the municipality of Amsterdam and, furthermore, 36 smaller municipalities within the Randstad. The AMA has been described as composed of densely urbanised areas alternated with peri-urban areas where a low population density and an intermingling of built and unbuilt features are visible, which were often neglected in regional planning and development strategies. This course encouraged students to consider interrelations between urban, peri-urban, and rural areas when coping with future challenges, such as climate change, and a more efficient/circular use of natural resources. This was combined with the goal of achieving resilient regional spatial systems that consist of complementary functions and spatial qualities within the territory.

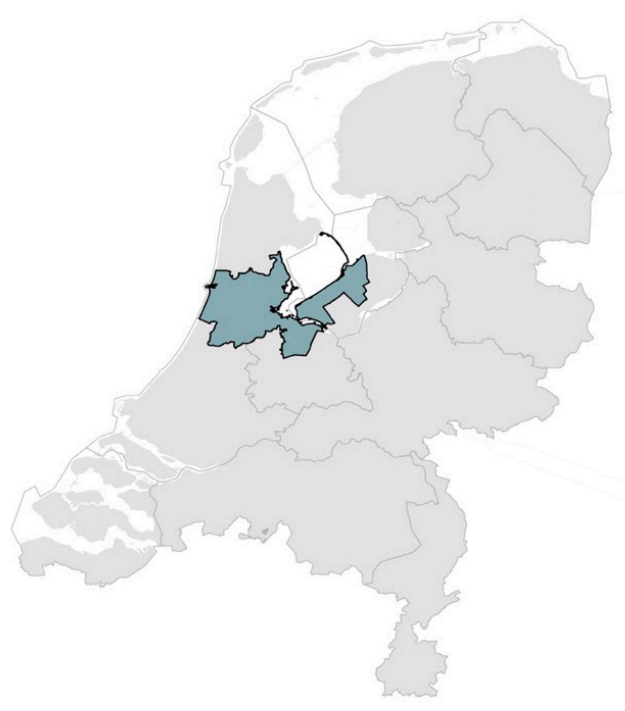

Figure 1. The boundaries of the Metropolitan Area of Amsterdam Source: http://h2020repair.eu/casestudies/amsterdam-nl/, redrawn by authors.

To do so, the 'regional design' approach of the course was applied to (1) explore spatial conditions, socio-economic trends, and correlated environmental issues at the regional level, (2) define spatial strategies toward more circular future scenarios for the Amsterdam Metropolitan Area. This 
edition of the studio within the academic year 2018-2019 benefitted from the collaboration with the Deltametropolis Association (Vereniging Deltametropool), and from the expertise gained through the project REPAiR, as previously outlined (More information could be found on the 'Quarter Guide Q3 2018-2019. MSc2 Urbanism. Faculty of Architecture and the Built Environment. Spatial Strategies for the Global Metropolis' (only available in printed version). Both authors co-taught in this edition of the studio and tutored the student's work, as reported in this paper).

In spring 2017, the Dutch Ministry of Interior Affairs and Kingdom Relations published a national housing agenda by projecting a demand for a million new homes in the Netherlands until 2030 [47]. Within this context, as the region attracting the largest portion of growth, the AMA plans to build 230,000 homes by 2040 [48]. Although a quick response to housing demands is reasonable, ideas about strategies to meet such demands are debated controversially. Besides the rising housing price and issues related to affordability, there is also concern about the environmental footprint that a hurried housing production may leave behind, and a threat to the diverse and highly appreciated natural landscapes. Furthermore, if a single perspective is adopted when dealing with short-term housing shortages, other longer-term spatial agendas might suffer from a lowered urgency, especially those dedicated to climate adaptation e.g., the implementation of sustainable energy schemes. Therefore, the emphasis of the assignment was on integral approaches that could consider the complexity and long-term scope of regional spatial development with two conceptual frameworks providing guidance for design and planning approaches, notably CE and 'spatial justice.'

Students were asked to combine the aspects of $C E$, spatial justice, and reuse of land, when coping with the above-mentioned (short-term) housing demands and (long-term) future challenges such as climate change. Specifically, the theme of CE included for this course sub-themes of construction and demolition waste cycles, food and organic waste cycles, and renewable energy cycles from which students can choose to focus on. Moreover, the regeneration of wastescapes, particularly in peri-urban areas, was deepened as a key aspect in most of the students' works.

Students worked in groups of four to five people on a regional design exercise in the R\&D studio (Research and Design studio). This studio was organised into two main phases.

The first one concerned an analysis phase that focused on understanding the current regional development trends and problems. A 'scientific' approach was used in this phase in which students were asked to show theoretical and empirical 'evidences' supporting their arguments. Analytical tools (such as GIS, space syntax, etc.) and methods (such as material flow analysis, SWOT analysis, multi-criteria analysis, etc.) were provided as knowledge input via lectures/workshops. Access to data was offered by the REPAiR project, which was one of the benefits of linking such a prestigious ongoing research project with design education (other benefits include, for example, connection with real stakeholders from the region). Building upon insights generated by synthesising such regional analysis, a spatial vision for the AMA was developed, which promoted a desirable future scenario that would serve as a normative framework with guiding principles for development. In this sense, the spatial vision is seen as a design product, a sketch of how the future should look like. The nature of a spatial vision is explorative, meant to build up new spatial agendas and bring them up for political debates. New questions will be generated by such exploration, which very likely lead to new research topics. Therefore, the course provided opportunities for students to present their spatial visions (in the form of mid-term presentations) to stakeholders of the region, so as to get feedback and questions to be considered for the second phase of the project.

The second phase aimed to develop a spatial strategy that could validate the imaginative spatial vision with practical actions. The strategy consists of a series of spatial interventions in the form of key projects and/or spatial policies, ordered chronologically, with actors and organisations involved in bringing spatial changes about. This consisted of a timeline that helped organise the different interventions over time in short, medium, and long-term periods, according to priorities identified by analysing the stakeholders' needs and the regional trends. In this phase, both research and design were mainly focusing on the development process, next to the spatial implications of the 
strategic interventions. The stakeholder analysis was instrumental for understanding governance issues and designing new models that are able to cope with future challenges. The tendency is transforming toward more participatory approaches, which will fundamentally change the role of design in the decision-making process. Therefore, the spatial strategy as a design product has its nature of experimentation-offering tools and methods of co-creation.

One can conclude that, in this course, both strategy and vision are spatial design products, using design as a tool to explore possibilities, demonstrate future images, and generate common interests among stakeholders. For example, the vision spatially describes a desirable future, and, therefore, should be persuasive, seek to convince, and enable and engage actors of action required to achieve the future scenario. It can be a pragmatic planning framework for a short time span (e.g., 20 years) or a near utopia projecting into the far future. This is a region supported only by renewable energy, no waste, and no further urban expansion, which would imply soil consumption. In light of the vision, the second design product, which is the development strategy, identifies concrete actions to be taken. It includes a definition of spatial interventions, i.e., projects and/or policies, and ordering of these interventions over a timeline, as previously mentioned. Moreover, an inventory of stakeholders that are involved in bringing spatial change about is also included. Students were asked to visualize the three components of a development strategy, so that the development process and spatial implications of the crucial interventions could be demonstrated. It was required that the roadmap should consider certainties and uncertainties during the path of development, which will result in a resilient approach with respect to uncontrollable contextual changes. Thus, scenario building was encouraged as an instrument to develop such an approach.

Coping with the complexity of a region, as indicated above, in the research and design studio in one-quarter time (which consists of eight weeks of timeframe) is actually a challenging task. In this sense, we need to bear in mind that the students' work has limitations, e.g., in a full understanding of the ongoing spatial development trends, or in managing all the aspects of their design proposals. Nevertheless, supported by extra lecture/workshop sessions that could bring input on knowledge and skills related to regional analysis and design, the workflow in the R\&D studio was facilitated on a weekly basis. Students were encouraged to reflect on the following questions: 'What are the ongoing trends and issues at hand? How to analyse/interpret the regional spatial structure and the flows of people and materials? What are the potentials of the region and its more desirable future scenarios? How do they look like? What are the regional strategies that could direct transformation processes toward these scenarios, seeing the unintended outcome of deliberate actions by individuals and agencies? How to formulate spatial policies and strategic projects in line with such regional strategies?'

These questions led to a constant interaction between research and design. Although the studio work flow could follow a linear process, in reality it was rather cyclic, involving a revisiting of the narratives. Such a workflow indicates a 'scientific design' process known as the 'TU Delft Approach,' which is characterised by integration of evidence-based research and imaginative/intuitive design. A clear line of reasoning and convincing argumentation was required when developing appealing visualization materials. Furthermore, strong regional emphasis and territorial metabolism were present when coping with the complexity of future challenges while, at the same time, uncertainties related to the changing context and governance were considered seriously.

\subsection{Holistic Approach to Define Adaptive Strategies and Solutions for the Metropolitan Area of Naples}

The Master-level design studio 'Laboratory of Urbanism' of the MAPA Course 'Laurea Magistrale in Architettura Progettazione Architettonica' (the course carried out during the academic year 2019-2020 built on the knowledge developed within the REPAiR project. It was co-taught by Libera Amenta -Urbanism module — and Paolo Camilletti-Landscape module — with the teaching assistance of Pasquale Volpe, and further support of Federica Vingelli, Maria Simioli, and Valentina Vittiglio. For the general contents and objectives of the course please check the link: http://www.diarc.mapa.unina.it/index.php/didattica) held at the Department of Architecture of the University of Naples Federico II, aimed for the students to 
identify a new equilibrium for the Metropolitan Area of Naples (MAN) by exploring different strategies for circular and resilient landscapes. This was done through a 'research by design' approach. By considering the urban system as a whole, and by applying an interdisciplinary perspective, students explored new instruments of the contemporary urban projects that could contribute to establishing different non-linear processes of growth. This is based on the valorisation and recycling of local materials and territorial resources without further consumption of goods and virgin soils. Specifically, the course adopted a holistic approach for understanding and designing the spatial organization of the territory of the MAN by developing solutions that could enhance the territorial performance [22]. Students worked in groups of three to four people on design exercises exploring strategies to stimulate regenerative processes, which could reduce environmental depletion, while increasing and diversifying uses, and ameliorating the quality of life for citizens in a sustainable way. The laboratory focused on the interpretation of the changes that, happening in the territorial object of the study, could trigger new urban dynamics, especially the reduction of social inequalities. To do so, the course explored a complex Focus Area composed of 11 municipalities within the MAN [6,15]. This includes Naples (with the districts of Ponticelli, Barra, San Giovanni a Teduccio), Casoria, Afragola, Acerra, Caivano, Casalnuovo, Crispano, Cardito, Frattaminore, Volla, and Cercola (Figure 2).
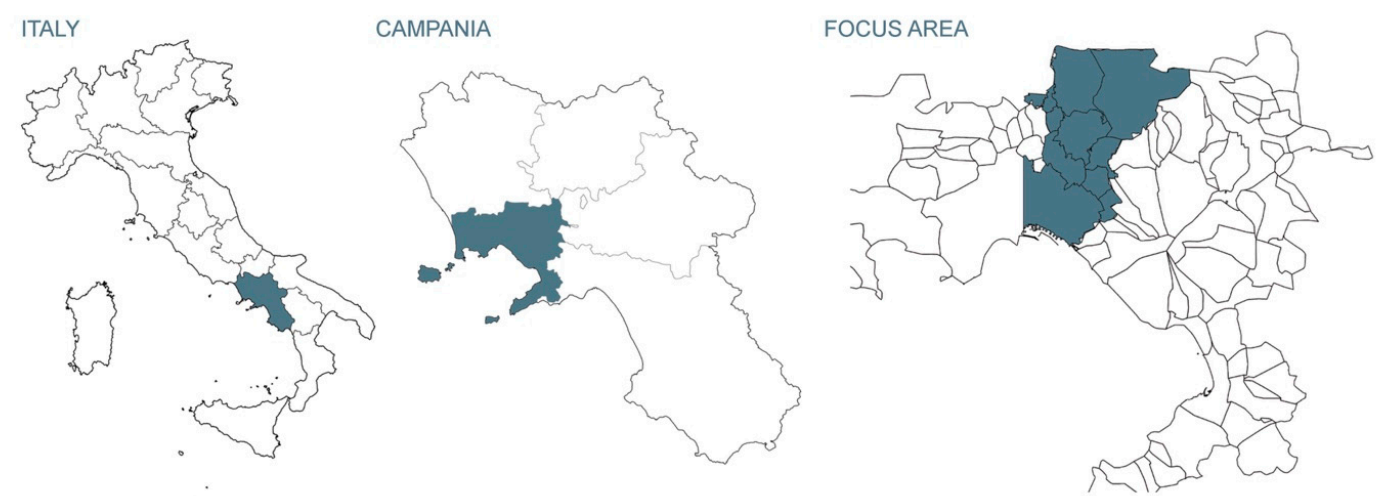

Figure 2. The boundaries of the Metropolitan Area of Naples (as in the REPAiR project). Source: drawing developed by the RestrAIN group composed by Di Vizia F., Napolitano S., Sannino S., and Visciano $\mathrm{M}$.

In this focus area, the features of urban and peri-urban territories are interwoven, and the challenges to eventually reach high levels of resilience and sustainability are many. In the MAN focus area, criticalities are connected such as toward (1) pollution and other environmental risks (e.g., related to the 'Terra dei fuochi' where waste is illegally deposited and burned), (2) to abandoned areas (e.g., former industrial areas) and other kind of wastescapes (e.g., areas in need of a new destination of use), (3) to the implementation of soft mobility, and to the scarce accessibility to certain municipalities by public transportation, and (4) to the presence of single-sectoral buildings/neighborhoods. However, if the interpretation of these challenges for the area is reversed, through explorative design, these criticalities could become the potentialities from which to re-start the identification of new strategies and solutions networked in an integrated large-scale vision. This was done by applying the principles of 'circular economy' considering soil as a valuable resource and implementing a mix of functions in underused areas (and wastescapes in general) for putting into effect new regenerative functions. Second, this was done by imagining to establish a consolidated network of stakeholders, or, third, by implementing integrated soft mobility systems, and so on.

The 'Laboratory of Urbanism' of the MAPA course has an interdisciplinary character, being composed of two integrated modules where the first one is about the specific topics of 'Urbanism' and the second one tackles the aspects related to the 'Landscape.' This organization of the course reflects the way the contemporary approach to design disciplines is giving importance to embrace an interdisciplinary perspective, which, in this case, tends to unify the shared interests of urbanism 
and landscape towards one integrated project. During the laboratory, the two modules attempted to work together with the aim to develop eco-innovative solutions and strategies for the MAN, which could enhance the urban quality and, at the same time, improve the environmental performance by increasing biodiversity in ecosystem services. This was done with the objective to inspire students to imagine an improvement of the quality of life of urban and peri-urban areas by meliorating the environmental sustainability and the circular economic development of the territory.

Thus, to reach these aims, the lab employed a background knowledge based on the combination of the themes of urban metabolism, urban adaptive reuse, CE, and spatial justice with a specific focus on the reuse of material and organic waste and on the regeneration of wastescapes $[5,6,14,15]$.

The course was organized according to two main phases. The first one was about the 'analysis and the representation' of the case-study area, while the second one was mostly related to the design of the vision and strategy.

In the first phase namely 'Understanding, and defining the site', students developed a site inspection through fieldworks (shown in Figure 3). This exercise enabled them to grasp the 'grain' of the territory, its special quality, and characteristics as well as to experience, through walking, photographing, and sketching the main challenges of the area, which were analysed only from a zenithal view, but through a human perspective. Moreover, they carried out desk research, which was followed by analysis and representation of the main systems that generally compose metropolitan areas, e.g., the network of infrastructures, the built environment, the environmental features, the metabolic flows (e.g., water and waste flows), and the representation of any other map useful to critically interpret problems and opportunities of the case-study area, including wastescapes. By systematizing the site [49] through the analyses of the elements, which constitute it and then represent them in schemes, concepts, and more elaborated drawings, students could already think about possibilities for adaptation. The analysis phase is already part of the design process [49]. In fact, in this first phase, the complexity of the study area was unpacked, and, thus, students were able to describe it, and, in this way, prepare the basis for eventually imagining how to intervene in the area with their design. Therefore, the experience of the site carried out in this way influenced the decisions made in relation to the site [49].
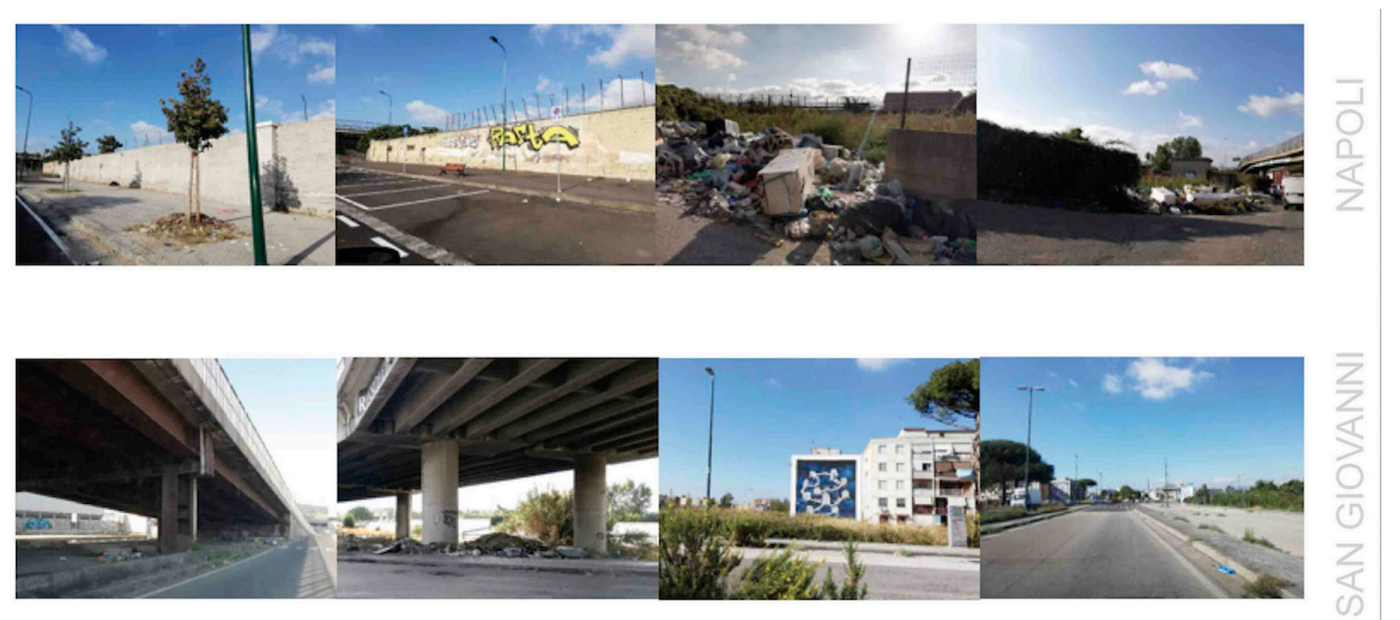

Figure 3. Understanding the site through fieldworks done by the 'RestrAIN' group. Source: elaboration by Di Vizia F., Napolitano S., Sannino S., and Visciano M.

In doing so, students experienced the case-study area at different scales in order to grasp the urban transformation that occurred over time, and the metabolic process still taking place.

After this deepening, students were able to select a 'Sample Area' within the limits of the 'Focus Area', which could exemplify all the features mapped for the 'Focus Area.' The definition of the boundaries of the 'Sample Area' was different for each group of study. It was considered an exercise in itself. Through it, students could be able to show their ability to identify and map smaller portions of 
the territory of their interest where the criticalities and potentialities were well represented, and where their intervention could be significantly implemented to trigger impacts on the whole focus area.

In preparation of the second phase of design, it was helpful for students to elaborate on a book of references by selecting examples of eco-innovative solutions and strategies from other national contexts and from abroad, which could be transferred and applied in the case-study area. These examples were used by students as a starting point to develop their territorial strategy. Since the solutions designed for the MAN had to be case-specific, students analysed the existing solutions imported from elsewhere by stressing their key principles that could be used and implemented locally in their design projects.

When the first phase was completed, students were able to give their interpretation to the definition of the site, which means to 'translate their research into individual approaches and methodologies and create visual representations of their findings: collages of knowledge' [50].

The second phase of the lab was about the interpretation and design of the site. At this stage, students developed a concept and a spatial vision through which to explain how to overcome the specific problems and challenges of the context investigated. Thanks to the development of the spatial vision, students could envision, in their work, an image of a possible future representing, (i) how to reuse wasted resources, including wasted lands namely wastescapes, (ii) how to regenerate and revitalise the territory by the provision of new and compatible functions, and (iii) how to design circular processes and trigger healthy metabolisms. In this way, the vision defines key principles for identifying a different kind of growth (Russo, 2014), which should be sustainable and resilient. The vision is the prerequisite for building the Territorial Spatial Strategy in the second phase of the lab. The Spatial Strategy could be developed through the composition of key projects or key policies, which should be smartly organised and adaptive, over a chronological timeline, in an integrated vision.

During the course, it was underlined that the design of a spatial strategy should not overlook the mapping of all stakeholders that could be involved in the previously mentioned strategy. To this aim, within the Laboratory of Urbanism, the theory of living labs, gamification, and other collaborative planning approaches were introduced and experienced by the students through additional seminars/workshops held during the course by external experts. This extended the scope of the methodology of 'research by design' from designing the physical environment to designing the process by actually experiencing this transition.

\section{Results}

In this part, the paper explores the different results of the design processes carried on by the TUDelft and UNINA urbanism lab courses, and, specifically, it deepens the modality in which students critically interlinked all the issues, which they explored, in the study of the AMA and MAN. Furthermore, in this section, the mutual process of learning developed at the same time of the experiments implemented by some of the students' groups is described. Moreover, some of the key arguments of the students' works are explained in this case and supported by some of their drawing elaborations. This was done to understand to what extent students could apply the methodological framework introduced within the courses in their works.

\subsection{Results of the Regional Design Studio-TU Delft}

The regional design course at TU Delft resulted in a variety of group projects focusing on the themes related to $\mathrm{CE}$ as well as re-use of wastescapes and spatial justice when coping with the housing demands in the AMA. In this case, two projects are used as examples to demonstrate how interdisciplinary and explorative design was used as a tool to experiment on spatial strategies that could stimulate the transition toward a more circular and livable region. They are the 'AMA.ABLE Energy' project and the 'ENCORE' project, focusing on the energy landscape and the construction cycles, respectively. Students defined the previously mentioned titles of their projects as a way to summarise their main idea for the region. Thus, they result as a kind of slogan, which aim to anticipate the complexity of their design process. 
The 'AMA.ABLE Energy' project started with an observation that the AMA is a spatially decentralized region characterized by an urban metabolism, which relies on non-renewable and centralized energy production. The latter is non-resilient, unequal, and does not promote social awareness of the necessary transition toward clean and renewable energy, and on the correlated landscape that derives from its implementation. In addition, ever increasing housing demand poses further challenges toward the achievement of sustainable urban growth. To reach the sustainability goal, students proposed a decentralized renewable energy network driven by the local housing development. The decentralized model has been considered with the potential to create a resilient energy network and to integrate it in the landscape with respect to the local identity (Figure 4). To deal with conflicts of interest among stakeholders on multiple scales, students created a development strategy based on serious gaming that integrates landscape, people, and energy on various scales. Social justice was addressed through such serious gaming in the decision-making process thanks to its nature of co-creation and participation of all the stakeholders. To support such a participatory process, a design toolbox was developed, providing guidelines for spatial development and linking the design of the regional spatial structure and the projects at a local level. The tools proposed have interdisciplinary and experimental characteristics, integrating industrial ecology knowledge from research and desirable spatial qualities of the place (Figure 5), identified circumstances on when and where to utilize them and for whom, as well as how to implement these tools. Most of these tools demonstrated methods for re-use of wastescapes in peri-urban areas of the AMA, and enhancing the identity of the regional landscape, when building new or upgrading old energy infrastructures in areas of housing development. By applying these tools, the participatory process of serious gaming is expected to result in multiple outcomes: enhanced circularity in terms of the re-use of land, energy transition with decentralized system, and a desirable energy landscape with a local identity. The methodology of 'research by design' was applied both in the design of the physical environment and the planning process, which demonstrated strong characteristics of experimentation. The actual solutions proposed by the group might not be perfect, but the approach itself was considered innovative, which opened up discussions on potentials of the peri-urban areas in facilitating the formation of a decentralized renewable energy network. This is more circular, fair, and contributes to a new local identity.

The 'ENCORE' project (Figure 6) focused on the construction and demolition waste cycles in the AMA. It started with a criticism on the extreme consequences of the current linear model of urban development on the environment, which can be experienced socially and spatially. Among these consequences, underused and polluted landscapes emerged, and they were defined as wastescapes often seen in peri-urban areas. It was recognized that the construction sector appears to be the most polluting sector in the linear economy due to its large need of raw materials and its considerable greenhouse emissions. In addition, it was pointed out that the AMA is also experiencing a high pressure on the housing market with increasing issues of affordability for lower and middle-income households. Therefore, the pressure on land as a resource for housing development is largely increasing. Thus, the 'ENCORE' project aimed to create an inclusive housing development process, which enabled the regeneration of wastescapes and the implementation of a circular construction network. This resulted in a vision and a strategy in which several key projects were introduced as experiments in accordance with a clear set of principles and values (1) regarding wastescapes: minimize the use of new territory, improve spatial qualities, (2) regarding housing: create more affordable housing by re-using underused lands and buildings, address accessibility of new housing areas through the re-use of existing infrastructure, (3) regarding construction: localize construction flows by means of production, transportation, and distribution, and use the production potential of the existing landscapes. The interdisciplinary nature of this project, backed up by research, lies in the synthesis of knowledge for typologies of wastescapes, landscape potentials for producing bio-based materials for construction, etc. The design tools proposed by the group contributed to the exploration of possible re-uses of wastescapes toward more desirable functions and spatial qualities. By testing these tools 
in the four chosen locations, combined goals of wastescape regeneration, circular construction and housing development were expected to be achieved.

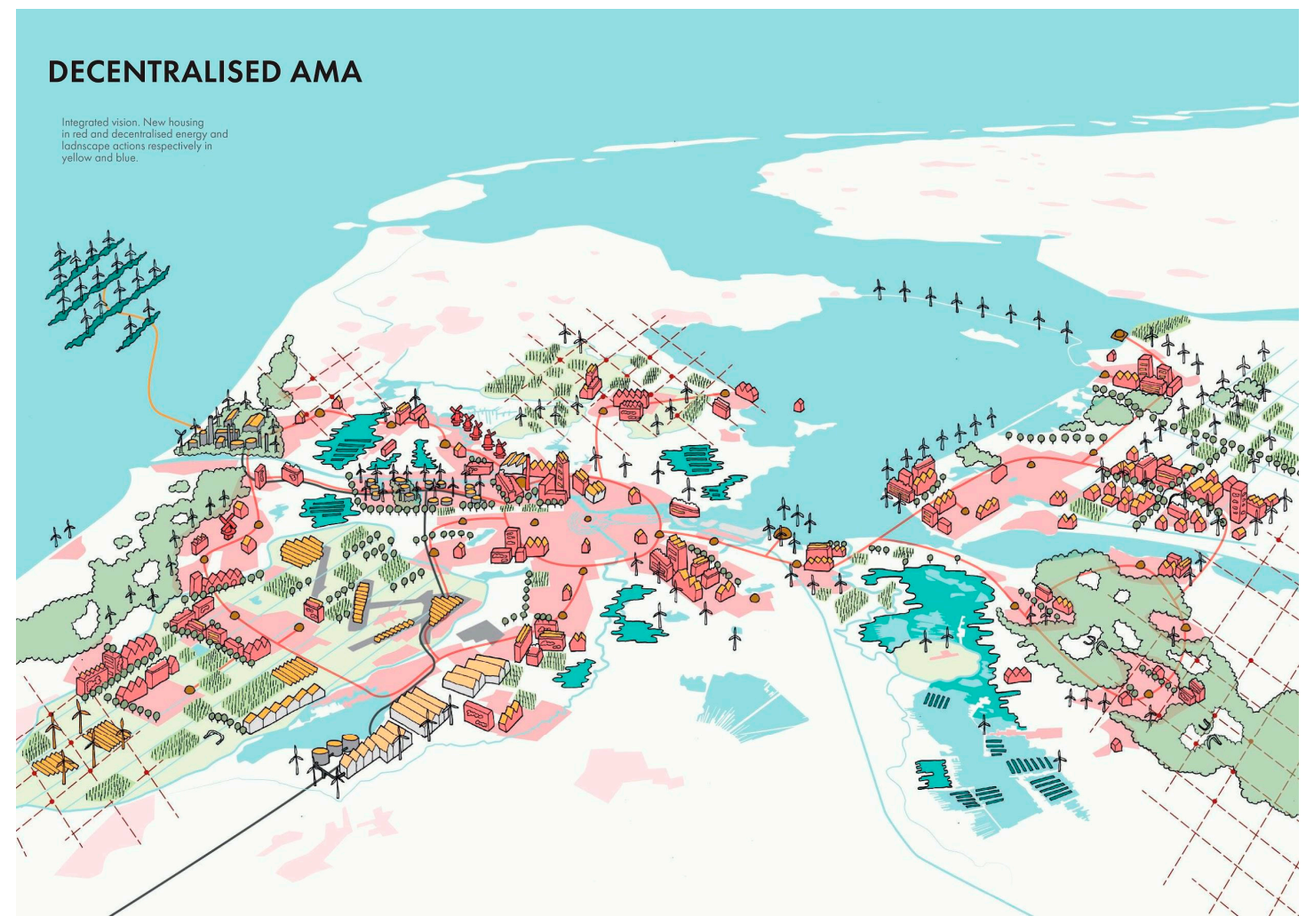

Figure 4. The integrated vision developed by the 'AMA.BLE energy' group, showing spatial qualities of the new housing areas in the new (decentralized) energy landscape of the Amsterdam Metropolitan Area. Source: drawing by Agliati S., Dimitriou I., van den Brink L., and Karadag E.

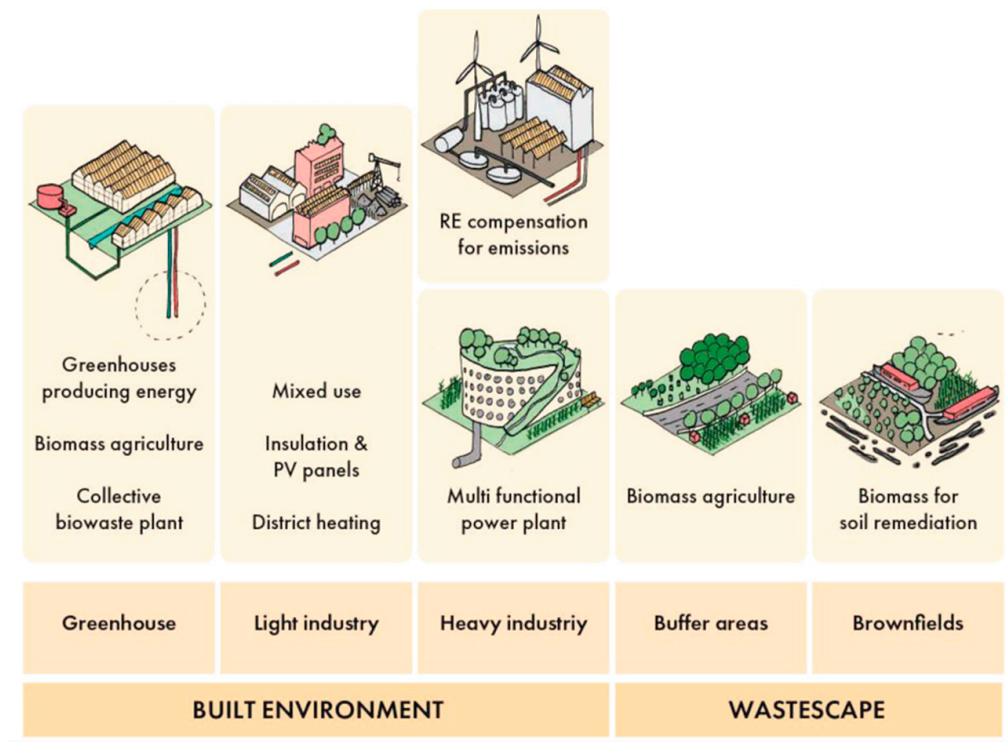

Figure 5. Landscape design principles developed by the 'AMA.BLE energy' project group, exploring the potentials of the re-use of wastescapes in the Amsterdam Metropolitan Area. Source: drawing by Agliati S., Dimitriou I., van den Brink L., and Karadag E. 


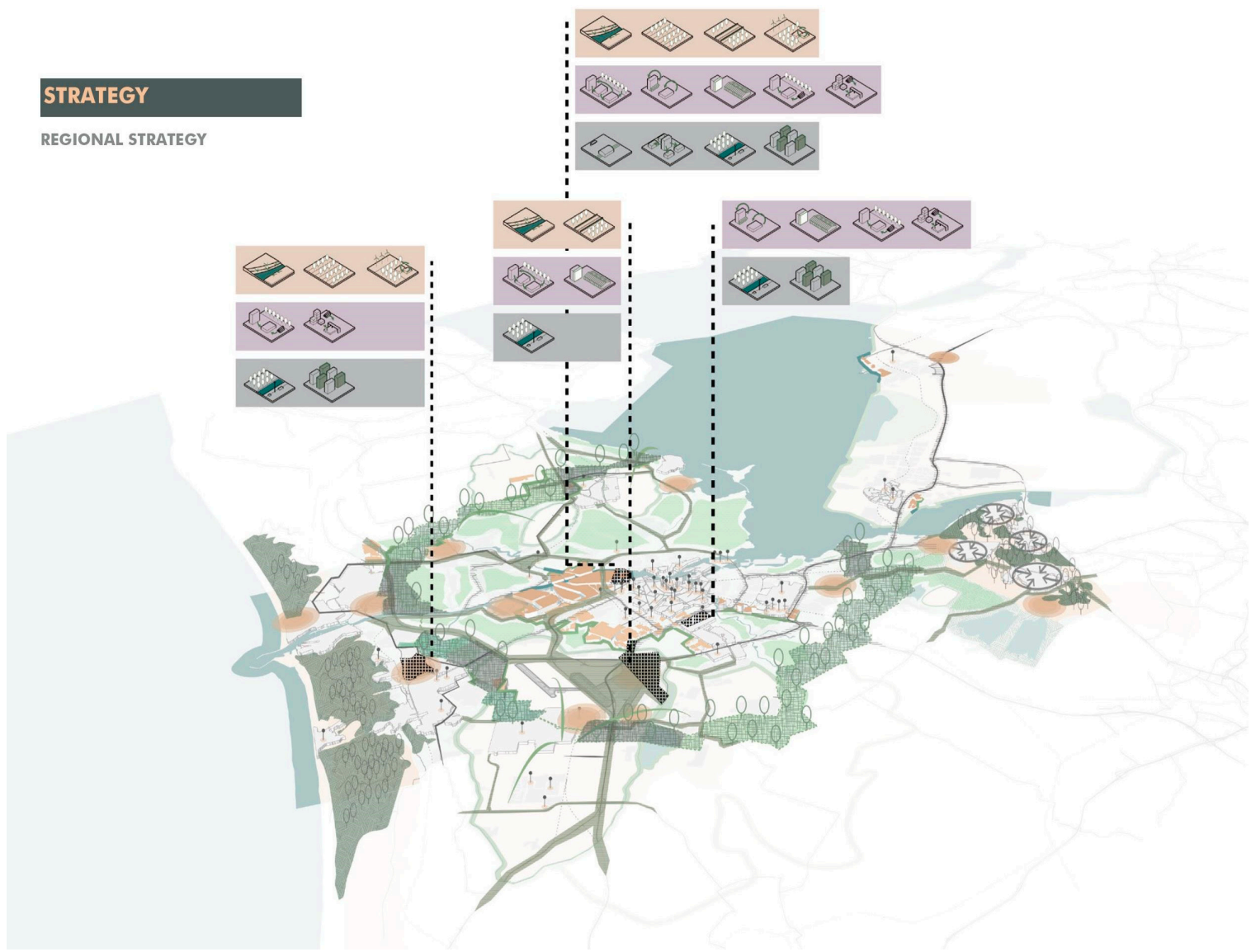

\section{STRATEGY}

DESIGN INTERVENTIONS
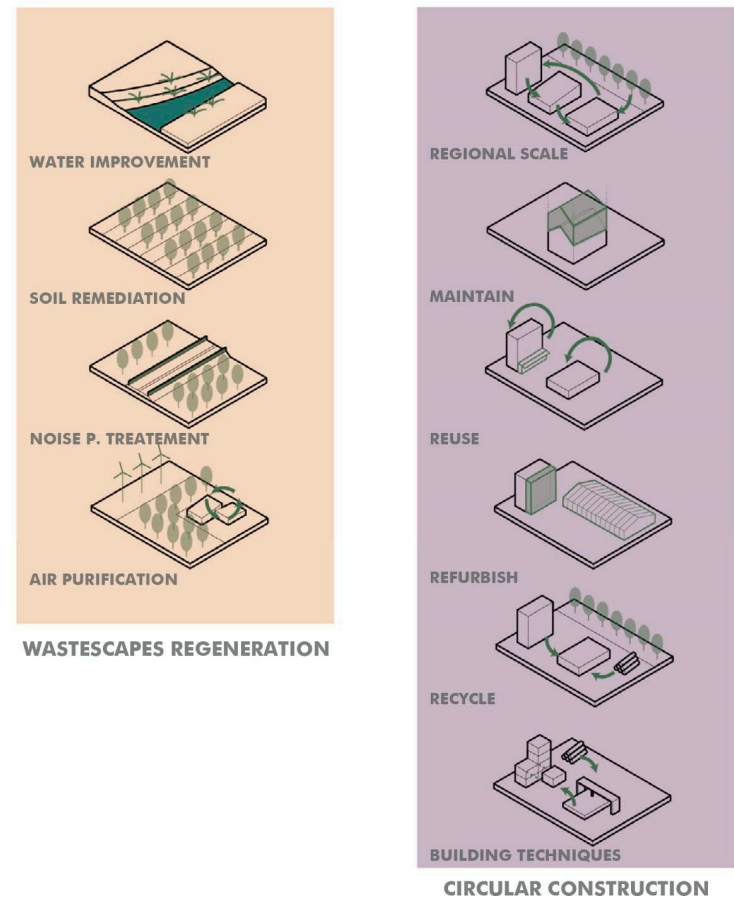

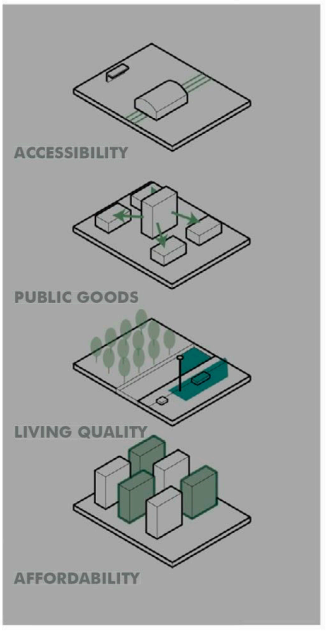

HOUSING

WASTESCAPES REGENERATION

CIRCULAR CONSTRUCTION

Figure 6. Tools developed by the 'ENCORE' project group for the regeneration of wastescapes, circular construction, and fair housing development, experimented in the four strategic projects in the AMA. Source: drawings by de Jong A., Boudouaya O., Li Y., and van den Berg N. 


\subsection{Results Laboratory of Urbanism MAPA, DiARC UNINA}

The outcome of the Laboratory of Urbanism of MAPA at DiARC in Naples was a diversity of group projects, which, according to the requirements of the course, identified strategies and solutions aimed to implement the principles of circularity, including the regeneration of wastescapes. In many of the cases, this was done by imagining starting from bottom-up initiatives developed locally with the involvement of the local community. In this way, solutions and strategies aimed to have an inclusive approach by considering all stakeholders' needs (by mapping all the stakeholders present in their study-area, and by foreseeing the implementation of Urban Living Labs [51] settings to start a co-design process). They were site-specific, and designed adopting a systemic and adaptive approach. They aimed to trigger sustainable and resilient urban and territorial transformations by increasing biodiversity and reducing water and soil pollution.

Two experiments were carried out by students as an example of the approach. The first one is the project entitled 'FELIX2begreen' (As in the case of the TU Delft course, also UNINA students identified a title that could be used as a slogan for their projects to summarise the main aim of their design proposal), in which, after developing a vision for the whole focus area, the study on the municipality of Acerra was deepened. In Acerra, the areas of intervention are crossed by Regi Lagni rivers (which are very polluted canals) by a very dense urbanised area, peri-urban territories, and agricultural fields. Furthermore, the area is characterised by the presence of historic manors being progressively neglected over time due to the continuous process of abandonment of the countryside, which need to be reinterpreted. In this project, the first phase of the 'research by design' process was useful to identify the criticalities and potentialities of three contexts within Acerra: (1) agricultural fields, (2) peri-urban areas, and (3) industrial zones. The key characteristic of the three analysed environments is the high presence of wastescapes. The latter have been used as a starting point to answer the following research question: 'How could a healthy relation be re-established between man, nature, countryside, and city through the regeneration of wastescapes?' Thus, students proposed to re-design parts of the territory of Acerra through a series of interventions organised by different subsequent steps, arranged along a specific timeline (Figure 7). First of all, the interventions foreseen in the short term (Step 1-from 2 to 5 years) are the ones which could be more easily implemented, or which need to start immediately and continue over time. These are the valorization of the ecological networks and the biodiversity along Regi Lagni rivers with the reconfiguration of their banks and the protection of the agricultural heritage. Moreover, in the first stage, the Living Labs for co-designing strategies for the regeneration of wastescapes are established. Second, in the medium term (Step 2 from 5 to 20 years), the project foresees the realization of the interventions, which require more resources to be implemented, as actions to integrate soft mobility in the existing infrastructural network, and the planting of species for phytoremediation. Third, in the long-term (Step 3 from 20 to 50 years), the actions are focusing mostly on the realisation of new buildings and facilities, and the realisation of important landscape projects such as the buffer zones of industrial areas or the implementation of the wetland machine. Furthermore, this group further deepened the study of a small portion of the municipality of Acerra in the north-west area, where they identified mono functionality and scarce public facilities, several cul-de-sacs in the infrastructure system, and social unease. Thus, their project envisioned the creation of new public facilities and infrastructures as well as public spaces for social gathering by reusing all the wastescapes, by valorising the existing settlements within a system of public green areas and cycle-pedestrian greenways. Moreover, the 'FELIX2begreen' project identified the possibility to insert a new residential area to complete the low-density settlements already present in the area (Figure 8a,b). 


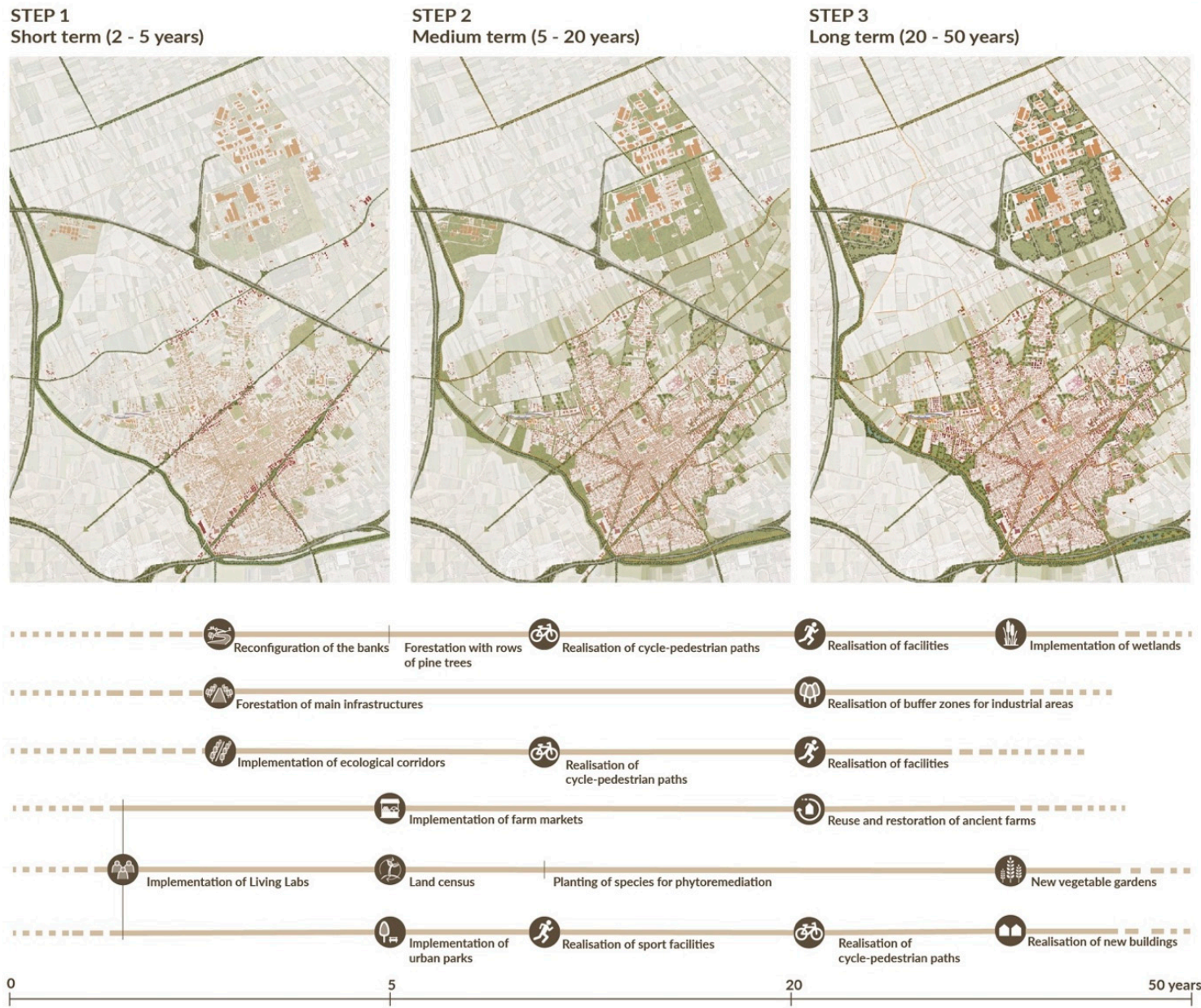

Figure 7. Image title: 'FELIX2begreen', a vision for Acerra organized in a timeline. Source: drawings by the MAPA students Luca Mola, Federica Paragliola, Luca Villani, and Alessia Villano.

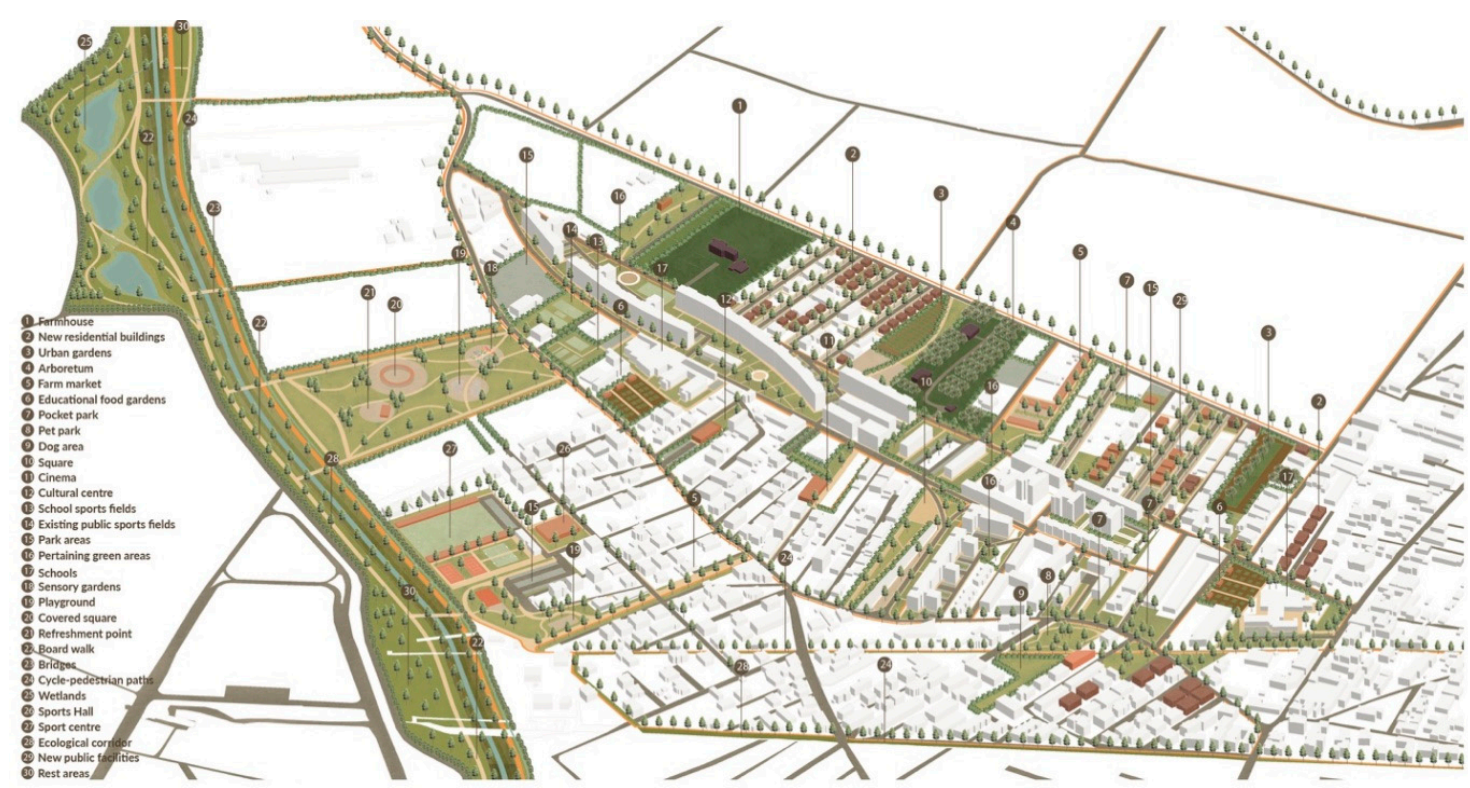

(a)

Figure 8. Cont. 


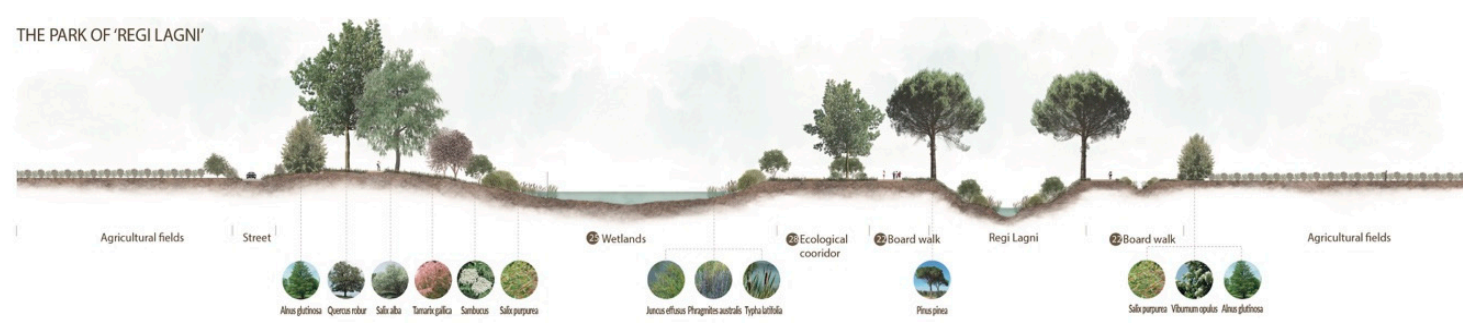

(b)

Figure 8. Image title: 'FELIX2begreen', overview of the interventions: bird's eye view (a) and section (b). Source: drawings by the MAPA students Mola L., Paragliola F., Villani L., and Villano A.

Another example is the 'RestrAIN' project, which focused on the Sample Area of Volla municipality. From their project title, students aimed to suggest that the topic of their interest was water. Among the different problems that this group identified, there was a need to 'hold back' the meteoric waters (hence, the title RestrAIN), which are difficult to be drained through the numerous sealed surfaces of the study areas. The main statement of this project is that targeted water management is the foundation for promoting biodiversity and for increasing renewable systems by promoting bottom-up actions. The vision for their sample area (Figure 9) resumes the major themes proposed for the focus area. Specifically, large green areas are envisioned, as well as the use of waterways suitably restored for the irrigation of the surrounding agricultural land, the redevelopment of the road junctions, and a new railway station on a route already foreseen by the plan and the recovery of the farms. These peri-urban areas will be re-connected through sustainable paths (cycle-pedestrian paths), which, at the same time, reconnect the urbanized fabric. The project strategy, also schematized in a toolbox (Figure 10), foresees the construction of lamination tanks in which the water will be properly collected. The land subtracted for the construction of the tanks is reused to create soil movements within the park, which is currently mostly flat. Adequate plants allow the purification of reusable water for irrigation of existing fields and shrub species provided in the park. Part of the project are also small rain gardens as well as gardens with a drainage system particularly effective in the recovery and disposal of rainwater. Soil remediation is carried out through species that are naturally capable of carrying out the phyto-extraction of metals, which makes the soil usable again. In addition, wooded areas are foreseen within the park and buffer zones adjacent to the viaducts to reduce noise pollution and purify the air. The increase in greenery will be necessary to promote the biodiversity of the area. The park is composed of squares equipped for sports and large outdoor theaters, which are all accompanied by areas for rest, refreshment, and services. Two of them are also water squares, which means squares that are floodable during events of heavy rain. Thus, they are suited for improving the resilience of the area. The increase in arable areas for public use is also important, which are associated with social activities in laboratories located within the park for the knowledge and reuse of waste products and raising citizens' awareness of the issue of agriculture. The whole area is crossed by cycle and pedestrian paths that allow crossing underneath the viaducts, which now appear as impassable barriers. The project will restore well-being and quality of life for the citizens. 


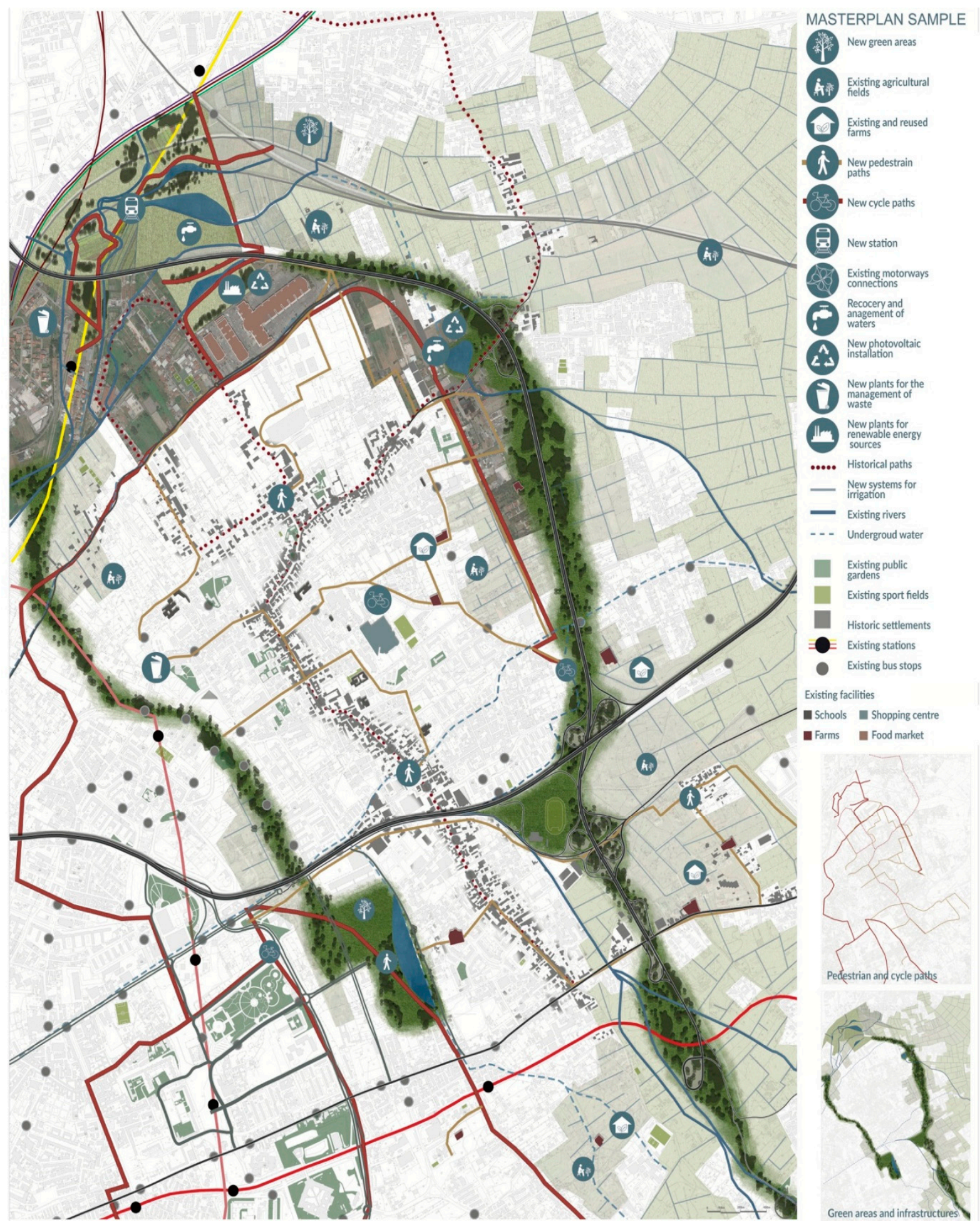

Figure 9. Example of the vision for the sample Area of Volla, developed by the 'RestrAIN' group. Source: drawing by Di Vizia F., Napolitano S., Sannino S., and Visciano M. 
TOOLBOX


Figure 10. Example of toolbox for the sample Area of Volla, and timeline, developed by the 'RestrAIN' group. Source: drawing by Di Vizia F., Napolitano S., Sannino S., and Visciano M. 


\section{Discussion}

\subsection{Comparison between the Two Courses}

The two courses have several similarities regarding the methodology of 'research by design' as well as the organization of the teaching activities. They both focused on questions of: (i) how to reuse wasted resources, including wastescapes, (ii) how to regenerate and revitalise the territory by implementing diverse functions, and (iii) how to design circular metabolisms. Both studios focused first on the research/analysis phase. Students conducted a mapping exercise and simultaneously gathered the necessary data to develop their exercise. In this way, they could show the spatial implications of the resource management on the structure of the territories of their study. This has paved the way for applying the methodology of 'research by design': exploring (spatial) potentials of the wastescapes in peri-urban areas by imagining future scenarios that are more desirable, which adds value and quality to the area. At a second stage, students defined spatial strategies and solutions, at different scales, crossing different disciplinary fields, and with different levels of investigations, for closing the loops, reusing wasted materials and neglected territorial resources, and by regenerating wastescapes. Both courses paid great attention to stakeholder analysis including research on governance models based on which students experimented with interdisciplinary design strategies (toolboxes are often used for such experimentation). They developed in various strategic locations/areas. This has extended the scope of design from designing physical forms to defining participatory processes.

In a nutshell, students of both courses demonstrated, despite time constraints, to be able to deal with the complexity of peri-urban areas by applying different design tools in their research experiments conducted at different scales. Furthermore, this was done by attempting to include the diverse points of view of several disciplines at the same time. This was also experienced through further design workshops held during the course (e.g., workshops based on gaming). Furthermore, they mostly applied a systemic methodology by trying to consider the challenges that were interpreted as great potentials (especially within peri-urban areas) for developing adaptive strategies and solutions.

\subsection{Pros and Cons of the Implementation of 'Research by Design' Methodology in the Studio Setting}

This paper aimed to link design education with research activities as part of an innovation process toward a holistic urban resilience. In this sense, students' design work was regarded as a valuable source of innovation. According to the experience of these two courses, students were able to think out of the box when imagining future scenarios. Although solutions were drawn with feasibility in mind, they were relatively free from political and economic constraints than practitioners. Students of these two courses, by focusing deeply on their case, were, in most of the cases, eventually capable of embracing the territorial complexity of the cases. They conducted experiments, which were appreciated by the REPAiR project team, seen as valuable for research because of the unforeseen results and new research insights. Students themselves also appreciated the scientific and societal relevance of their design assignment, access to data, and knowledge on CE from an ongoing research project as well as the opportunities of getting feedback from real stakeholders from the region. This was a learning process most of them never experienced before, as many of them mentioned 'a very different course.'

As indicated earlier, students' work also showed some limitations and obstacles, which is worth mentioning. A commonality among the different projects was that the study of the metabolic flows, even if it was considered of great interest, being new to all the students, was not deepened enough due to the difficulty to gather data related to flows and to represent them.

The process of selecting the sample areas to deepen their design exercises appeared to be another complex task to be completed immediately for some students' groups since they could not always synthesize multiple research outputs at the same time. This also indicated a challenge for applying the methodology of 'Research by Design.'

Moreover, it was a demanding task for these young students to develop Spatial Strategies that could represent a roadmap toward a desirable future. In fact, in some cases, only some solutions were 
presented, which were not really functioning in a systemic and integrated way, due to limited time and limited knowledge on these technical solutions. Nevertheless, the 'spirit' or characteristics of experimentation are visible in all the solutions and steps.

Obstacles in using the catalogue of solutions for developing site-specific eco-innovative solutions and strategies for the case study lied in the fact that some solutions could be entirely transferable in other contexts, while others might need minor adaptations. Furthermore, others could be less suitable for transfer due to important contextual barriers [52]. Thus, the use of reference projects for the design process is not an immediate and simple task. It requires a great capacity of abstraction and flexibility in the adapting the existing solutions to the specificities of the context. This is another challenging task related to linking research and design, from understanding how things work to proposing and validating how the world could be.

Lastly, they mostly applied a systemic methodology that is plausible. However, sometimes 'naiveness' was unavoidable due to time limitations.

\section{Conclusions}

This paper introduced and compared how material resource flows were managed and wastescapes were reused in urban and regional design, in two university design studios at the Urbanism Department of TUDelft, in the Netherlands, and at the Department of Architecture of the University of Naples Federico II, in Italy. Thanks to the comparability between the two courses, in terms of the selected regions of the AMA and MAN (both as study cases of the REPAiR project), as well as the teaching methods and complimentary design scales, the comparison has led to conclusions on how a 'research by design' approach could be used in university design studio settings as a methodological tool to experiment with circularity for imagining more resilient and regenerative metropolitan areas.

The explorative nature of design is well-suited with wicked problems, which do not have one clear solution and always demand adaptation [13]. The assignments which both university design studios defined were complex challenges that called for holistic and systemic approaches in which spatial design (both at the regional and local levels) could contribute to experimenting adaptive strategies that bring positive changes to the current situation, the plausible improvement of spatial qualities, and imagination of desirable future scenarios. In doing so, the analytical/scientific research and constructive/experimental design components of the studio works were interwoven throughout the process, which kept the experiments going with the support of a systemic and interdisciplinary methodology. Content-wise, these two design studios both had aims of stimulating the transition towards more circular regions, which could be more resilient and regenerative in the future. This includes spatial strategies at the regional level facilitating the reuse of resources (including land), closing the waste cycles, and creating eco-innovative solutions at the local scale based on holistic understanding of resilience and regenerative approaches. From the perspective of scarcity in land resources, the reuse of wastescapes becomes the key, and has been placed at the center of experimentation in both design studios. Therefore, as seen from the example of student projects, the peri-urban settings, such as the areas near the harbor and airport in the Amsterdam case, became relevant in spatial strategies, where flows are concentrated and wastescapes can be identified. Furthermore, both courses emphasized the importance of social justice in addition to the technical aspects of the adaptive strategies. This has resulted in an extra contribution of these two design courses toward enriching the methodology of 'research by design' especially when coping with issues of circularity in city-regions (from designing the physical forms and technical solutions to defining participatory processes). Lastly, the limitations of the research by design methodology applied in these two university studios include the depth of understanding on the complex issues and data availability due to the limited experience of students and time frame. To a certain extent, this can be coped with by offering input on knowledge and skills related to the assignment as well as access to data with the support from an ongoing research project, i.e., the REPAiR project. 
The paper tried to fill in the two knowledge gaps mentioned earlier in the introduction session, namely the clarification of the research by design methodology, and accommodating resource flows in urban and regional design, based on the experiences of the two university design studios. Those integral approaches developed by students can be inspiring for research and practice in these case study areas concerning resilience. However, the innovative insights brought by these two courses are mainly in their pedagogical approaches. Therefore, further investigation is still needed to integrate research, education, and practice, so that both the methodology of 'research by design' and content-related design strategies for circular, resilient, and regenerative regions can be consolidated.

Author Contributions: All the parts of this article have been written and approved by both the authors L.A. and L.Q. All authors have read and agreed to the published version of the manuscript, including the revised version. However, the Section 1, Section 2.1, Section 3, Section 3.1, Section 4, Section 5.2 are by L.A. and L.Q.; the Section 2.2, Section 3.2, Section 4.2, Section 5.1 are by L.A.; the Section 4.1, and Section 6 are by L.Q. Conceptualization, methodology, validation, and investigation, are by L.A. and L.Q. Writing-original draft preparation is by L.A. Writing-review and editing is by L.A. and L.Q. Visualization are by the students reported in the paper. Supervision is by L.A. and L.Q., Funding Acquisition, REPAiR project.

Funding: This research is done within the framework of the European Horizon 2020 funded research 'REPAiR: REsource Management in Peri-urban AReas: Going Beyond Urban Metabolism'. This project has received funding from the European Union's Horizon 2020 research and innovation programme under grant agreement No 688920. This article reflects only the author's view. The Commission is not responsible for any use that may be made of the information it contains.

Acknowledgments: We are grateful to all the students of the Regional design studios of the Course 'Spatial Strategies for the Global Metropolis' (February to April 2019) held at Delft University of Technology (TU Delft), and to all the students of the Master-level design studio namely 'Laboratorio di Urbanistica' (in English: 'Laboratory of Urbanism') of the MAPA Course 'Laurea Magistrale in Architettura Progettazione Architettonica', taught at the Department of Architecture of the University of Naples Federico II (UNINA), in Italy (September 2019 to January 2020). Moreover, we thank all the colleagues of the TUDelft studio, and specifically Alexander Wandl and Verena Balz, and the colleagues of the UNINA studio specifically Paolo Camilletti and Pasquale Volpe who contributed largely to the design and the development of the courses. Thanks also to Federica Vingelli, Maria Simioli, and Valentina Vittiglio, who contributed in tutoring students during the MAPA course at UNINA. Moreover, we thank all the colleagues who participated in both studios organising and holding seminars and workshops. Furthermore, special thanks go to the colleagues of the REPAiR team and especially to TUDelft and UNINA research teams of the REPAiR project, on which this paper builds on. Lastly, we appreciated the comments of the two anonymous reviewers who contributed toward substantially increasing the quality of this paper.

Conflicts of Interest: The authors declare no conflict of interest.

\section{References}

1. Neuman, M. The Compact City Fallacy. J. Plan. Educ. Res. 2005, 25, 11-26. [CrossRef]

2. EEA. European Environment Agency More from Less-Material Resource Efficiency in Europe 2015 Overview of Policies, Instruments and Targets in 32 Countries; EEA Report No 10/2016; Publications Office of the European Union: Brussels, Belgium, 2016.

3. Global Footprint Network Ecological Footprint-Global Footprint Network. Available online: https: //www.footprintnetwork.org/our-work/ecological-footprint/ (accessed on 19 November 2018).

4. Berger, A. Drosscape: Wasting Land in Urban America; Princeton Architectural Press: New York, NY, USA, 2006; ISBN 1568987137.

5. Amenta, L.; van Timmeren, A. Beyond Wastescapes: Towards Circular Landscapes. Addressing the Spatial Dimension of Circularity through the Regeneration of Wastescapes. Sustainability 2018, 10, 4740. [CrossRef]

6. REPAiR. Process Model for the Two Pilot Cases: Amsterdam, the Netherlands E Naples, Italy. Deliverable 3.3; EU Commission Participant Portal: Brussels, Belgium, 2018; Grant Agreement No 688920.

7. Huggett, R.; Lindley, S.; Gavin, H.; Richardson, K. Physical Geography: A Human Perspective; Huggett, R., Lindley, S., Gavin, H., Richardson, K., Eds.; Arnold, Hodder Headline Group: London, UK, 2004; ISBN 0340809620.

8. Du, N. Integrating Surface Water Management in Urban and Regional Planning: Case Study of Wuhan in China; University of Twente, Faculty of Geo-Information Science and Earth Observation (ITC): Enschede, the Netherlands, 2010; ISBN 978-90-6164-283-1. 
9. Ellen MacArthur Foundation. Cities and the Circular Economy for Food; Ellen MacArthur Foundation. 2018. Available online: https://www.ellenmacarthurfoundation.org/assets/downloads/Cities-and-the-circulareconomy-for-food-1.pdf (accessed on 1 June 2020).

10. Gemeente Amsterdam Amsterdam Circular 2020-2025 Strategy 2020. Available online: https://www. amsterdam.nl/en/policy/sustainability/circular-economy/ (accessed on 1 June 2020).

11. Cardoso, M.A.; Brito, R.S.; Pereira, C.; Gonzalez, A.; Stevens, J.; Telhado, M.J. RAF Resilience Assessment Framework-A Tool to Support Cities' Action Planning. Sustainability 2020, 12, 2349. [CrossRef]

12. Rosemann, J. The Conditions of Research by Design in Practice. In Proceedings A. of the International Conference "Research by Design"; DUP Science, Delft University Press: Delft, the Netherlands, 2001; pp. 63-68.

13. Roggema, R. Research by Design: Proposition for a Methodological Approach. Urban Sci. $2017,1,2$. [CrossRef]

14. Amenta, L. Beyond WASTESCAPES Opportunities for Sustainable Urban and Territorial Regeneration; TU Delft Open: Delft, the Netherlands, 2019; ISBN 978-94-6366-156-0.

15. REPAiR. Introduction to Methodology for Integrated Spatial, Material Flow and Social Analyses REPAiR Deliverable 3.1; EU Commission Participant Portal: Brussels, Belgium, 2017; Grant Agreement No 688920. [CrossRef]

16. Williams, J. Circular cities. Urban Stud. 2019, 004209801880613. [CrossRef]

17. Mcrit. Urban-Rural Narratives and Spatial Trends in Europe: The State of the Question; Ministry of Environment, and Rural and Marine Affairs Lead Partner: Barcelona, Spain, 2010.

18. Wandl, A.; Rooij, R.; Rocco, R. Understanding the Planning of Open-Spaces in Territories-in-Between: Dupuy's Network Urbanism Approach Applied to Areas in-between Urban and Rural. In Proceedings of RSA EUROPEAN-CONFERENCE-2012 Delft Networked Regions and Cities in Times of Fragmentation: Developing Smart, Sustainable and Inclusive Places. 13-16 May 2012; Delft University of Technology: Delft, the Netherlands, 2012.

19. Wandl, A. Territories -in- between: A Cross-Case Comparison of Dispersed Urban Development in Europe; Delft University of Technology: Delft, the Netherlands, 2019.

20. Ricci, L. Peri-Urban Livelihood and Adaptive Capacity: Urban Development in Dar Es Salaam. Cons. Submiss. Platf. 2020. [CrossRef]

21. Wandl, A.; Balz, V.; Qu, L.; Furlan, C.; Arciniegas, G.; Hackauf, U. The Circular Economy Concept in Design Education: Enhancing Understanding and Innovation by Means of Situated Learning. Urban Plan. 2019, 4, 63. [CrossRef]

22. van den Boomen, T.; Frijters, E.; van Assen, S.; Broekman, M.; van Eijck, G.; Kums, M.; Lofvers, W.; Naafs, S.; van Spaandonk, T.; Steketee, A.; et al. Urban Challenges, Resilient Solutions: Design Thinking for the Future of Urban Regions; Simon Franke-Trancity, Pia Pol/Astrid Vorstermans-Valiz: Amersfoort, the Netherlands, 2017; ISBN 9789492095336.

23. Wall, R. Between Worlds: Architectural Exercises Between the Metageographic and Microspecific. ARCHIS 2004, 2, 42-54.

24. de Jong, T. Kleine Methodologie voor Ontwerpend Onderzoek; Boom Meppel: Amsterdam, the Netherlands, 1992.

25. Neuman, M.; Zonneveld, W. The resurgence of regional design. Eur. Plan. Stud. 2018, 26, 1297-1311. [CrossRef]

26. Dehaene, M. Horizontal metropolis: Issues and challenges of a new urban ecology statements. In The Horizontal Metropolis between Urbanism and Urbanization; Viganò, P., Cavalieri, C., Barcelloni Corte, M., Eds.; Springer: Cham, Switzerland, 2018.

27. REPAiR. D5.3 Eco-Innovative Solutions Naples; EU Commission Participant Portal: Brussels, Belgium, 2018; Grant Agreement No 688920.

28. REPAiR. D 5.2 Catalogue of Solutions and Strategies for Amsterdam; EU Commission Participant portal: Brussels, Belgium, 2018; Grant Agreement No 688920.

29. REPAiR. Handbook: How to Run a PULL Deliverable 5.4.; EU Commission Participant Portal: Brussels, Belgium, 2018; Grant Agreement No 688920.

30. van Timmeren, A. The Concept of the Urban Metabolism (UM); Delft University of Technology, Faculty of Architecture, Department of Urbanism, Chair Environmental Technology \& Design: Delft, the Netherlands, 2014.

31. Kennedy, C.; Cuddihy, J.; Engel-Yan, J. The changing metabolism of cities. J. Ind. Ecol. 2007, 11, 43-59. [CrossRef]

32. Ferrão, P.; Fernandez, J. Sustainable Urban Metabolism; MIT Press: Cambridge, MA, USA, 2013; ISBN 9780262316941. 
33. Ellen. MacArthur Foundation What Is The Circular Economy? Available online: https://www. ellenmacarthurfoundation.org/circular-economy/what-is-the-circular-economy (accessed on 2 April 2020).

34. ARUP. The Circular Economy and the Built Environment; ARUP: London, UK, 2016.

35. EEA European Environment Agency. Circular Economy in Europe. Developing the Knowledge Base; European Environment Agency: Luxembourg, 2016; Volume 2.

36. Lacy, P.; Rutqvist, J. Waste to Wealth. The Circular Economy Advantage; Palgrave Macmillan: London, UK, 2015.

37. Longato, D.; Lucertini, G.; Dalla Fontana, M.; Musco, F. Including Urban Metabolism Principles in Decision-Making: A Methodology for Planning Waste and Resource Management. Sustainability 2019, 11, 2101. [CrossRef]

38. van Timmeren, A.; Henriquez, L.; Reynolds, A. ReciproCities. A Dynamic Equilibrium; Delft University of Technology (TUD): Delft, the Netherlands, 2013; ISBN 978-94-6186-256-3.

39. Steffen, W.; Richardson, K.; Rockström, J.; Cornell, S.E.; Fetzer, I.; Bennett, E.M.; Biggs, R.; Carpenter, S.R.; de Vries, W.; de Wit, C.A.; et al. Planetary boundaries: Guiding human development on a changing planet. Science 2015, 347, 1259855. [CrossRef]

40. Raworth, K. Doughnut Economics: Seven Ways to Think Like a 21st Century Economist; Chelsea Green Publishing: White River Junction, VT, USA, 2017; ISBN 1847941370.

41. European Commission. Living within Planetary Boundaries-The Safe and Just Space for the People of Europe Environmental Pillar Consultation Response to: 7 th Environmental Action Programme (7EAP) Consultation. 2012. Available online: https://ec.europa.eu/environment/action-programme/pdf/Position\% 20Papers\%20received/Environmental\%20Pillar.pdf (accessed on 1 June 2020).

42. EC. Towards a Circular Economy: A Zero Waste Programme for Europe; European Commission: Brussels, Belgium, 2014.

43. Wandl, A.; Nadin, V.; Zonneveld, W.; Rooij, R. Beyond urban-rural classifications: Characterising and mapping territories-in-between across Europe. Landsc. Urban Plan. 2014, 130, 50-63. [CrossRef]

44. Donadieu, P. Campagnes Urbaines; Actes Sud, Ecole Nationale Superieure du Paysage: Arles, France, 1998; ISBN 2742720235.

45. Mininni, M. Prefazione. In Pierre Donadieu. Campagne Urbane. Una Nuova Proposta di Paesaggio Della Città; Donzelli Editore: Roma, Italy, 2006.

46. Mininni, M. Approssimazioni Alla Città; Donzelli Editore: Roma, Italy, 2012; ISBN 27427202359782742720231.

47. Den Haag: Ministerie van Binnenlandse Zaken en Koninkrijksrelaties (BZK). Ministerie Van BZK 2018. Nationale Woonagenda, the Netherlands, 2018. Available online: https://www.rijksoverheid.nl/ministeries/ministerie-vanbinnenlandse-zaken-en-koninkrijksrelaties/organisatie/organogram (accessed on 1 June 2020).

48. Metropoolregio Amsterdam (MRA). Wonen in de Metropoolregio Amsterdam 2017; Metropoolregio Amsterdam: Amsterdam, the Netherlands, 2018.

49. Baudoin, G.S. Interpreting Site: Studies in Perception, Representation, and Design; Routledge, Taylor and Francis Inc.: New York, NY, USA, 2015; ISBN 9781317695615.

50. Hein, C.; De Martino, P. Designing post-carbon Dunkirk with the students from TU Delft. 2018. Available online: https://pure.tudelft.nl/portal/en/publications/designing-postcarbon-dunkirk-with-thestudents-from-tu-delft(b8245581-d44d-4034-83ec-1a348468c9a5).html (accessed on 1 June 2020).

51. Steen, K.; van Bueren, E. Urban Living Labs. A Living Lab Way of Working; Amsterdam Institute for Advanced Metropolitan Solutions Delft University of Technology: Delft, the Netherlands, 2017.

52. Dąbrowski, M.; Varjú, V.; Amenta, L. Transferring circular economy solutions across differentiated territories: Understanding and overcoming the barriers for knowledge transfer. Urban Plan. 2019, 4, 52-62. [CrossRef]

(C) 2020 by the authors. Licensee MDPI, Basel, Switzerland. This article is an open access article distributed under the terms and conditions of the Creative Commons Attribution (CC BY) license (http://creativecommons.org/licenses/by/4.0/). 